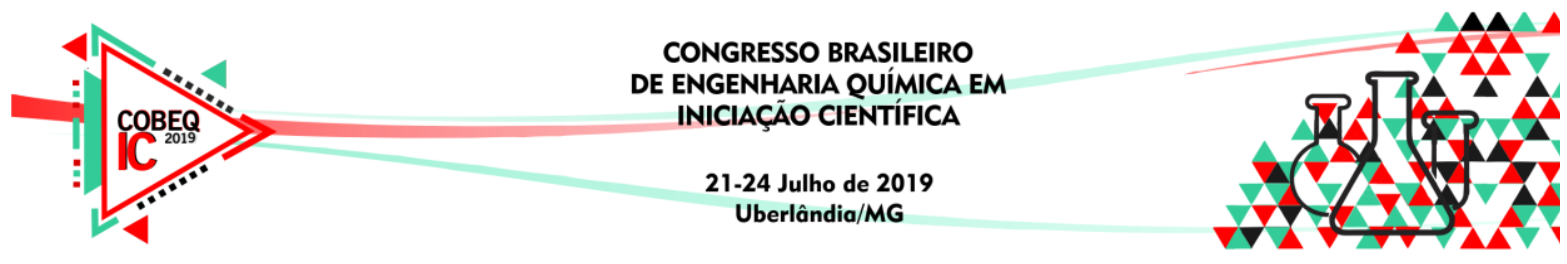

\title{
OBTENÇÃO DE UM CARVÃO ATIVADO A PARTIR DO MESOCARPO DO Cocos nucifera PARA REAÇÃO DE ESTERIFICAÇÃO
}

\author{
J. S. RODRIGUES ${ }^{1}$, T. F. SILVA ${ }^{1}$, P. K. L. S. VALENÇA ${ }^{1}$, I. L. LUCENA ${ }^{1,}$ e Z. M. \\ SANTOS $^{1}$ \\ ${ }^{1}$ Universidade Federal Rural do Semi-Árido, Departamento de Engenharia e Tecnologia. \\ E-mail para contato: thamyres.freire@hotmail.com
}

\begin{abstract}
RESUMO - Este trabalho apresenta o estudo da fibra de coco (Cocos nucifera) seco como matéria-prima para a obtenção de carvão ativado a ser utilizado como catalisador para produção de biodiesel. Foi estudada uma forma de utilizar a fibra do mesocarpo do coco seco impregnado com ácido sulfúrico e carbonizado produzindo catalisador para reação de esterificação. A vantagem de usar subprodutos agrícolas como matéria-prima para carvão ativado, carvão vegetal e combustível é que essas matérias-primas são renováveis e potencialmente menos caras de fabricar. A avaliação das variáveis da produção do catalisador foi feita pelo cálculo da conversão da reação de esterificação. A amostra com maior conversão foi a 2 com 69,21\% utilizando concentração de ácido sulfúrico de $10 \%$, temperatura de impregnação de $25{ }^{\circ} \mathrm{C}$ e temperatura de carbonização de $200^{\circ} \mathrm{C}$. Foi feito uma análise estatística para estudar as interações entre as variáveis na conversão da reação sendo a interação entre a temperatura de impregnação e temperatura de carbonização mais significativa para um intervalo de confiança de 95\%. Os carvões ativados a partir de biomassa considerada resíduo podem apresentar boas conversões na reação de esterificação e ser uma escolha viável economicamente.
\end{abstract}

\section{INTRODUÇÃO}

Por definição, biodiesel é um substituto natural do diesel de petróleo, que pode ser produzido a partir de fontes renováveis como óleos vegetais, gorduras animais e óleos utilizados para cocção de alimentos (fritura). Na reação de esterificação, o processo de obtenção acontece com a reação entre um ácido graxo com um mono álcool para formar ésteres. Segundo Oliveira et al. (2008) essa reação tem como catalisador um ácido. O uso de catalisadores heterogêneos é uma alternativa para produzir ésteres metílicos de ácidos graxos. Esse tipo de catálise apresenta certas vantagens em relação à homogênea, pois simplifica o processo de purificação do biodiesel com a redução de efluentes aquosos, possibilita o uso de alcoóis de elevado peso molecular e a reutilização dos catalisadores (SUPPES et al., 2001).A utilização de resíduos agroindustriais é uma alternativa para desenvolver adsorventes de baixo custo, contribuindo para a redução dos custos na eliminação dos resíduos (BHATNAGAR; SILLANPÄ̈̈, 2010). O coco, por exemplo, é um fruto que após o consumo do seu líquido é prontamente descartado. Para este trabalho, o material escolhido para sintetizar o carvão ativado foi obtido a partir das fibras obtidas do mesocarpo do coco seco. $\mathrm{O}$ ácido sulfúrico foi 


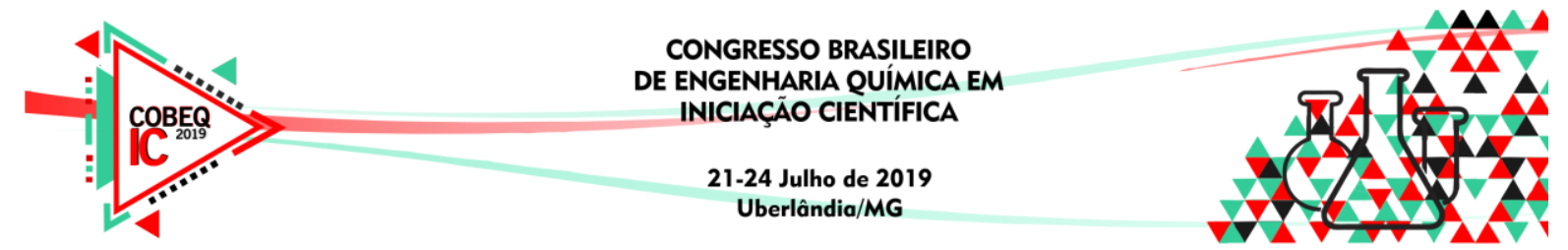

escolhido por se tratar de um ácido bastante forte, ou seja, por suas propriedades ativantes e por se tratar de ácido barato. Usando as condições de reação de esterificação de $10 \%$ de ácido sulfúrico, com temperatura de impregnação do ácido na fibra de $45^{\circ} \mathrm{C}$ e uma carbonização de $200{ }^{\circ} \mathrm{C}$, o estudo de Martins (2018) com carvão ativado a partir do coco apresentou uma amostra com conversão de $69,15 \%$.

Para a síntese do carvão ativado envolve duas etapas, são elas: ativação do produto e a carbonização do material. A ativação tem como objetivo ampliar os diâmetros dos poros finos e criar novos poros. Já a carbonização consiste na decomposição térmica do material, em que poros muitos finos e fechados são criados nesta etapa.

\section{MATERIAIS E MÉTODOS}

Os equipamentos utilizados estão apresentados na Tabela 1.

Tabela 1 - Equipamentos

\begin{tabular}{|c|c|}
\hline Equipamento & Modelo/ Marca \\
\hline \hline Shaker & SL-222 / (Solab) \\
\hline Mufla & LM-SS 16L \\
\hline Agitador de peneiras & Lucadema \\
\hline Estufa & TE-394/2 / Tecnal \\
\hline Balança Analítica & Marte AY220 \\
\hline Agitador de peneiras Mesh/Tyler & Lucadema \\
\hline Liquidificador & Mondial \\
\hline
\end{tabular}

O experimento foi realizado em duas partes: preparação do catalisador e reação de esterificação, seguindo o método utilizado por Martins (2018), pois por testes preliminares mostraram que as faixas das variáveis escolhidas resultavam em conversões consideráveis. $\mathrm{O}$ esquema de preparação do catalisador é apresentado na Figura 1.

Figura 1 - Esquema de preparação do carvão ativado.

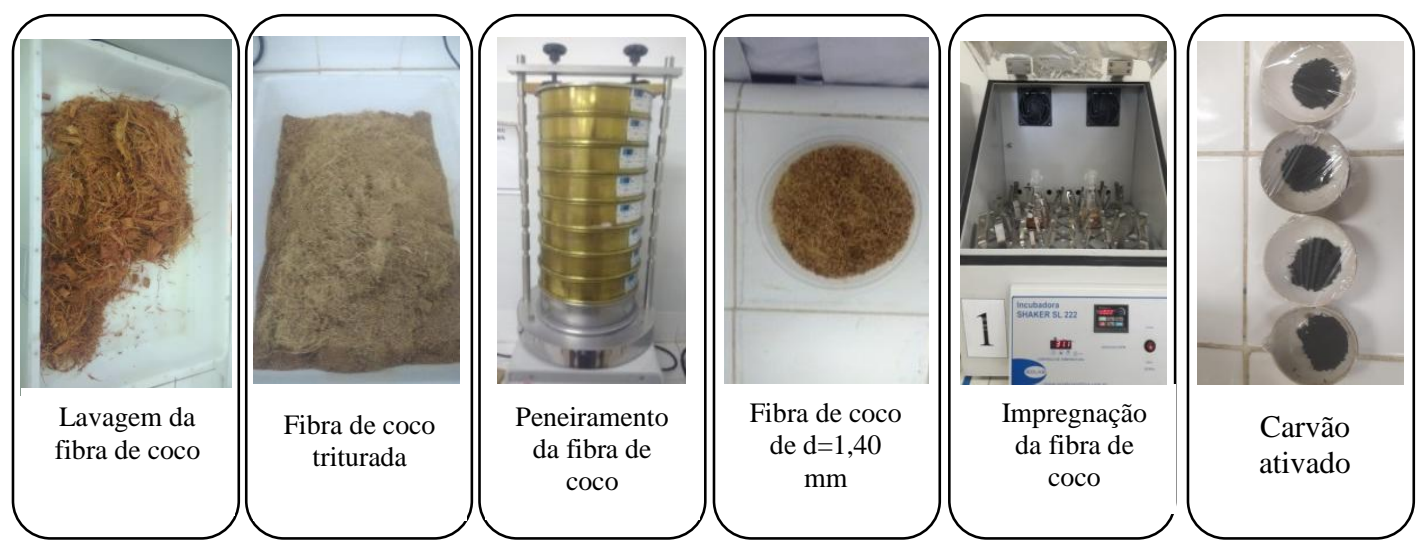

O coco seco utilizado foi de Tibau, RN. O mesocarpo do coco foi retirado manualmente, lavado, seco em estufa por $24 \mathrm{~h}$ à $35^{\circ} \mathrm{C}$ para retirada de excesso de água, triturado em liquidificador, separado por peneiras com auxílio de agitador de peneira. Foi escolhido o diâmetro médio de 1,40 mm da fibra peneirada. Para a impregnação do carvão foi 


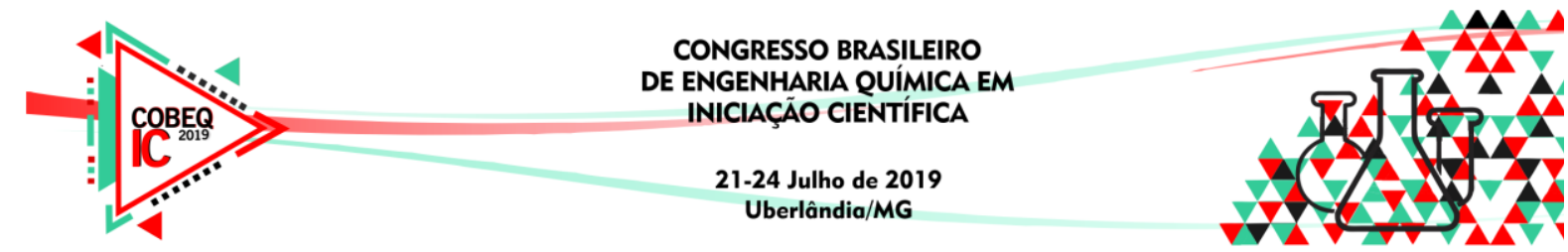

usado ácido sulfúrico (Micro-química Ltda) com agitação de $150 \mathrm{rpm}$ em um Shaker durante $3 \mathrm{~h}$ nas concentrações e temperaturas apresentadas na Tabela 2. As amostras foram filtradas por filtração simples, colocadas em vidro de relógio e levadas para estufa e mantidas por $24 \mathrm{~h}$ à $35^{\circ} \mathrm{C}$. As amostras secas foram colocadas na mufla com rampa de aquecimento de $1^{\circ} \mathrm{C} / \mathrm{min}$ nas temperaturas presentes na Tabela 2 e mantidas por $2 \mathrm{~h}$ em cada uma delas.

Tabela 2 - Variáveis estudadas do planejamento experimental,

\begin{tabular}{|c|c|c|c|}
\hline & -1 & 0 & +1 \\
\hline \hline Concentração do ácido sulfúrico & $5 \%$ & $7,5 \%$ & $10 \%$ \\
\hline Temperatura de impregnação do ácido & $25^{\circ} \mathrm{C}$ & $35^{\circ} \mathrm{C}$ & $45^{\circ} \mathrm{C}$ \\
\hline Temperatura de carbonização da amostra & $200^{\circ} \mathrm{C}$ & $225^{\circ} \mathrm{C}$ & $250^{\circ} \mathrm{C}$ \\
\hline
\end{tabular}

$\mathrm{Na}$ reação de esterificação os reagentes foram álcool metílico P.A-ACS (Dinâmica Ltda) e ácido oleico P.S (Dinâmica Ltda). A proporção adotada entre eles foi de 6:1 de álcool para o ácido. Foi acrescentado de $1 \%$ em massa de amostra de catalisador obtido a partir da fibra de coco em relação a massa do ácido oleico. A matriz experimental utilizada foi $2^{3} \mathrm{com}$ triplicata no ponto central totalizando 11 amostras e o branco, que foram levados ao um shaker sob uma temperatura de reação de $35^{\circ} \mathrm{C}$ e uma agitação de $150 \mathrm{rpm}$, durante um período de 24 h para reação de esterificação.

Com o filtrado é possível calcular índice de acidez e a conversão da reação. Esse índice diz respeito a quantidade hidróxido de sódio P.A-ACS Micropérolas (Dinâmica LTDA) necessário para neutralizar os ácidos graxos existentes na amostra. O procedimento experimental adotado para determinação do índice foi o mesmo utilizado por Lucena (2008) e a conversão da reação foi calculada determinando o índice de acidez da amostra. Inicialmente para sua neutralização o álcool etílico comercial 92,8 $8^{\circ}$ INPM (Itajá) foi titulado com uma solução de $\mathrm{NaOH}$ 0,1 mol/L utilizando fenoftaleína como indicador ácido-base.

As Equações 1 e 2 foram usadas para determinar o índice de acidez e a conversão da reação a partir do volume de $\mathrm{NaOH} 0,25 \mathrm{~mol} / \mathrm{L}$ que foi gasto na titulação.

$$
\begin{aligned}
& I A=\frac{W \times F \times N \times 56_{0} 11}{M} \\
& \text { Conversão }(\%)=\frac{I A_{0}-I A}{I A_{0}} \times 100
\end{aligned}
$$

Os dados foram tratados estatisticamente para obtenção de um modelo matemático para representar o experimento nas condições estudadas e analisar a interação entre as variáveis através de gráficos.

\section{RESULTADOS E DISCUSSÕES}

A Tabela 3 apresenta a conversão obtida de cada amostra e as respectivas condições operacionais empregadas. 


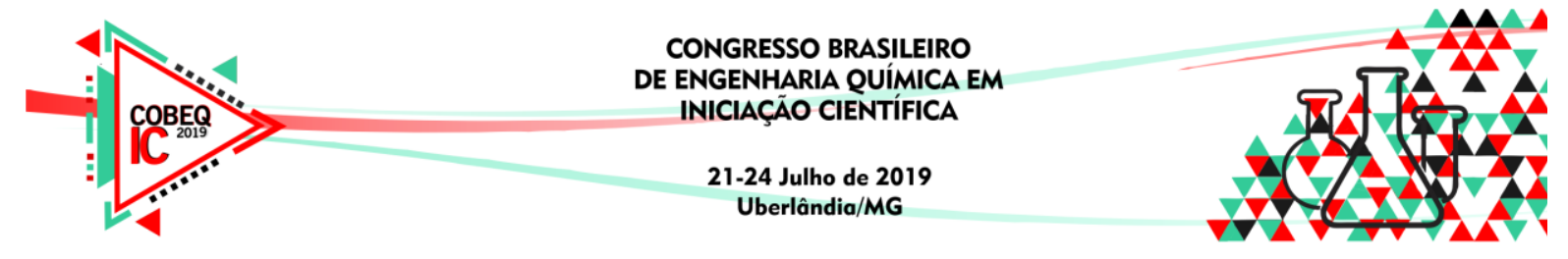

Tabela 3 - Resultado de conversão.

\begin{tabular}{|c|c|c|c|c|}
\hline Amostra & $\begin{array}{c}\text { Concentração } \\
\text { de ácido (\%) }\end{array}$ & $\begin{array}{c}\text { Temperatura de } \\
\text { impregnação }\left({ }^{\circ} \mathrm{C}\right)\end{array}$ & $\begin{array}{c}\text { Temperatura de } \\
\text { carbonização }\left({ }^{\circ} \mathrm{C}\right)\end{array}$ & Conversão (\%) \\
\hline \hline 1 & 5 & 25 & 200 & 44,17 \\
\hline 2 & 10 & 25 & 200 & 69,21 \\
\hline 3 & 5 & 45 & 200 & 47,50 \\
\hline 4 & 10 & 45 & 200 & 59,55 \\
\hline 5 & 5 & 25 & 250 & 16,23 \\
\hline 6 & 10 & 25 & 250 & 16,19 \\
\hline 7 & 5 & 45 & 250 & 9,00 \\
\hline 8 & 10 & 45 & 250 & 41,76 \\
\hline 9 & 7,5 & 35 & 225 & 39,00 \\
\hline 10 & 7,5 & 35 & 225 & 36,72 \\
\hline 11 & 7,5 & 35 & 225 & 32,85 \\
\hline
\end{tabular}

A amostra 2 foi a que apresentou maior conversão com a máxima concentração de ácido sulfúrico, e mínima temperatura de impregnação e carbonização. Martins (2018) também estudou o desempenho de um catalisador obtido da fibra do coco seco, com o diâmetro da fibra de $0,75 \mathrm{~mm}$, em uma reação de esterificação sendo sua metodologia a adotada neste trabalho. Para esse diâmetro a melhor conversão obtida foi na amostra 4. Assim podemos inferir que diferentes diâmetros da fibra durante a impregnação e carbonização levam a diferentes áreas superficiais, diferentes volumes de poros e consequente porosidade, por isso as conversões foram diferentes apesar das condições experimentais serem as mesmas.

De acordo com a Figura 2, a temperatura de carbonização foi a variável que se mostrou mais significativa com um intervalo de $95 \%$ de confiança. Esta variável obteve uma resposta de efeito negativa, isso significa que quanto menor a temperatura de carbonização maior é a resposta da conversão. A carbonização em temperaturas maiores pode levar a perda de grupos funcionais, ou seja, grupos de caráter ácido. Para que o ácido oleico se transforme em éster é necessário que o íon $\mathrm{H}+$ promova a protonação desse ácido para a entrada do álcool na cadeia levando a formação do éster, se o íon for desativado a altas temperaturas a conversão diminui.

Figura 2 - Gráfico de Pareto.

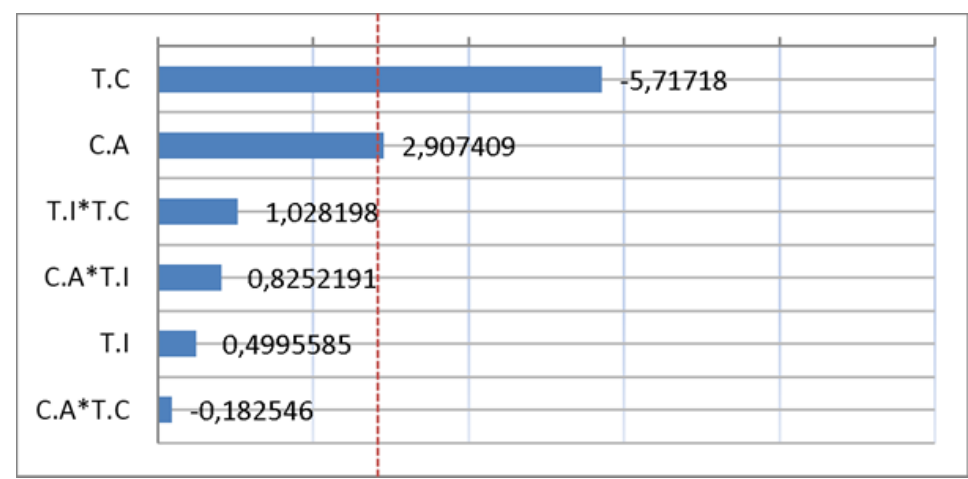

Os resultados obtidos correspondem a resposta de conversão da reação de esterificação, indicando um coeficiente de determinação $\left(\mathrm{R}^{2}\right)$ de 0,91518 . O modelo obtido mostrou-se adequado, porém pouco significativo para este estudo, um modelo não linear possivelmente representaria melhor os resultados. $\mathrm{O}$ modelo pode ser visualizado no gráfico da Figura 3. 


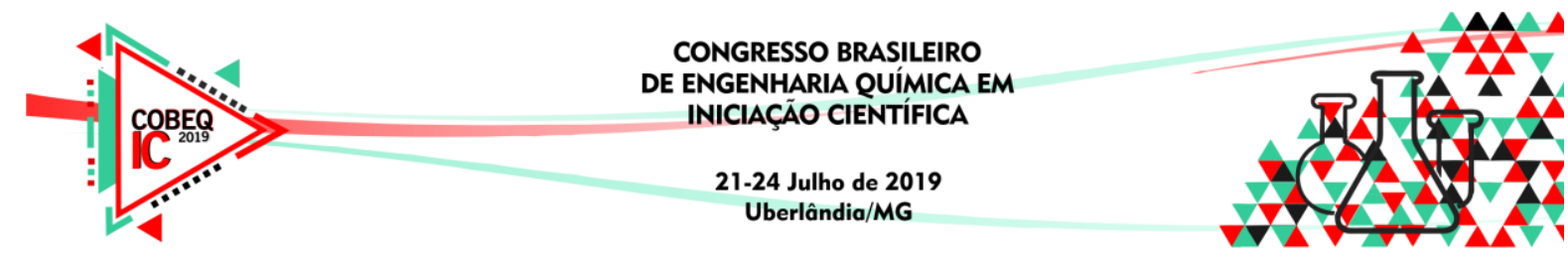

Figura 3 - Valores preditos x valores observados

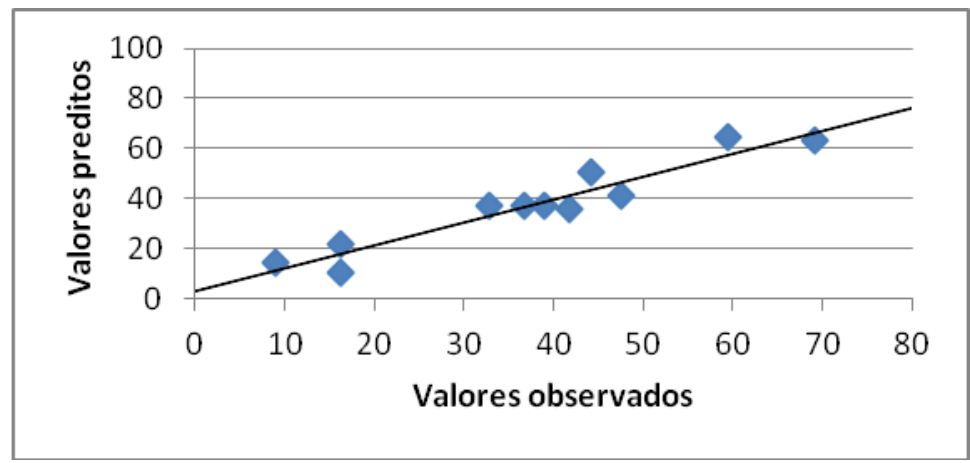

Os gráficos apresentados a seguir relacionam as variáveis e suas influências na conversão da reação. Pela Figura 4 (A) pode-se observar que a maior conversão será quando a concentração do ácido for máxima, percebe-se que nessa condição, a influência da temperatura de impregnação é muito pequena. Na Figura 4 (B), quanto menor a temperatura de carbonização, maior será o valor da conversão e a máxima conversão é obtida quando a concentração do ácido é a maior. Já na Figura 4 (C), a conversão é favorecida quando a temperatura de carbonização é mínima e a concentração do ácido exerce pouca influência. Através das análises das curvas de níveis abaixo observa-se que as maiores conversões foram obtidas para a faixa de maior concentração de ácido sulfúrico e menor temperatura de calcinação do processo de obtenção do catalisador a partir da fibra de coco.

Figura 4 - Gráficos de interações de variáveis. A- Concentração do ácido x Temperatura de impregnação. B- Concentração do ácido x Temperatura de carbonização. CTemperatura de impregnação $\mathrm{x}$ Temperatura de carbonização.
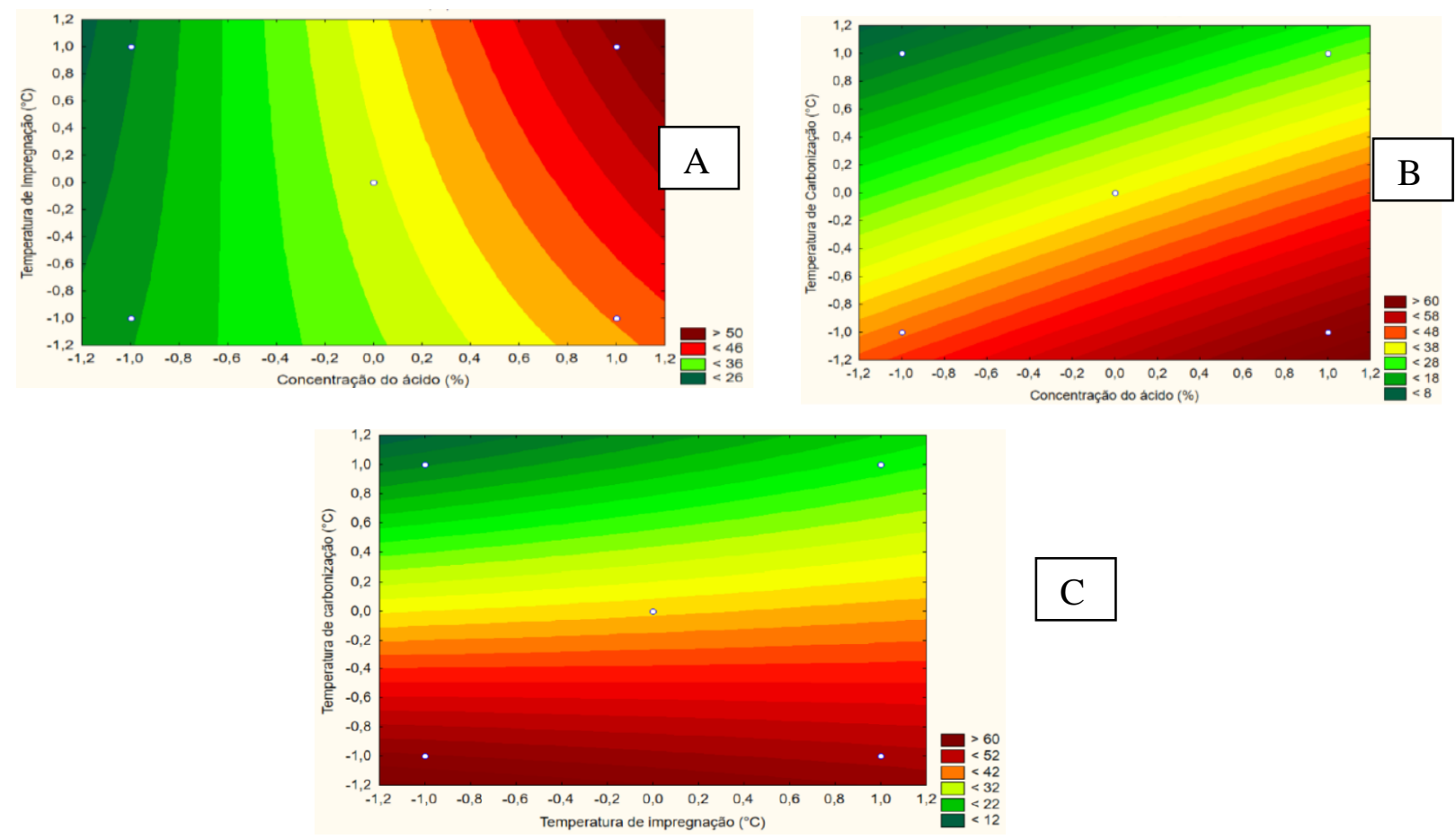


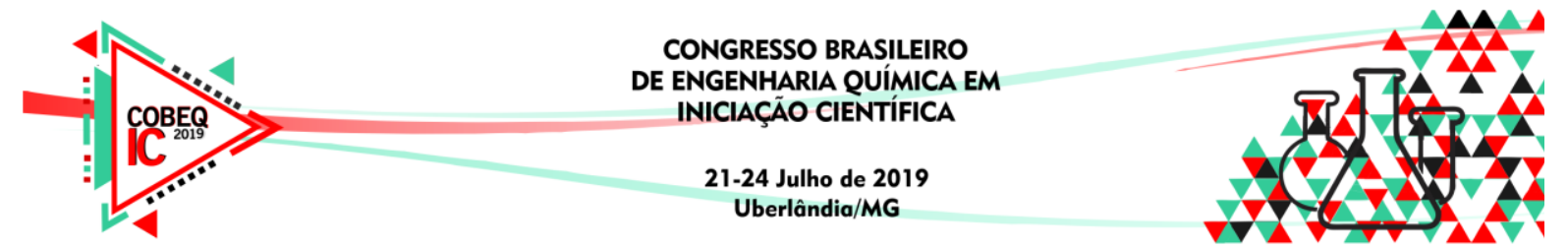

\section{CONCLUSÃO}

A temperatura de carbonização se mostrou a variável mais significativa na síntese do carvão ativado, sendo que quanto menor o valor, maior foi a conversão da reação de esterificação. Isso se deve muito provavelmente a manutenção dos sítios ativos, quando utilizado uma temperatura de carbonização menor. A maior conversão obtida foi de $69,21 \%$ da amostra 2. Portanto, as condições que mais favoreceram a síntese do catalisador para a reação foram utilizando solução com concentração de $10 \%$ de ácido sulfúrico, uma temperatura de impregnação de $25{ }^{\circ} \mathrm{C}$ e uma temperatura de carbonização de $200{ }^{\circ} \mathrm{C}$. O modelo matemático de primeira ordem com uma confiança de $95 \%$ foi considerado adequado para descrever os dados experimentais.

\section{NOMENCLATURA}

\begin{tabular}{|l|l|}
\hline Símbolo & Significado \\
\hline \hline F & Fator de correção da solução de $\mathrm{NaOH}$ \\
\hline IA & Índice de acidez do experimento em questão \\
\hline IAo & Índice de acidez do experimento em branco \\
\hline $\mathrm{M}$ & Massa de amostra utilizada para análise \\
\hline $\mathrm{N}$ & Normalidade da solução de $\mathrm{NaOH}$ \\
\hline $\mathrm{V}$ & Volume de $\mathrm{NaOH}$ utilizado para atingir o ponto final da titulação da amostra \\
\hline
\end{tabular}

\section{REFERÊNCIAS}

BHATNAGAR, A; SILLANPÄÄ, M. Utilization of agro-industrial and municipal waste materials as potential adsorbents for water treatment-A review. Chem. Eng. Journal, [s.1.], v. 157, n. 2-3, p.277-296, 2010.

LUCENA, I. L. Otimização do processo de obtenção de biodiesel através da adsorção da água formada durante a reação de esterificação. Dissertação (Mestrado em Engenharia Química) - Universidade Federal do Ceará, Fortaleza. 2008.

MARTINS, B. F. Utilização da fibra de coco-da-baía como catalisador heterogêneo na reação de esterificação para produção de biodiesel. 2018. 10 f. TCC (Graduação) - Curso de Ciência e Tecnologia, Universidade Federal Rural do Semi-Árido, Mossoró, 2018.

NASCIMENTO, R. F. et al. Adsorção: aspectos teóricos e aplicações ambientais. Fortaleza: Imprensa Universitária, 2014. 256 p.

OLIVEIRA, F. C. C.; SUAREZ, P. A. Z.; SANTOS, W. L. P. Dos. Biodiesel: Possibilidades e Desafios. Química Nova na Escola, v. 30, n. 28, p. 2068 2071, maio 2008. Disponível em: <qnesc.sbq.org.br/online/qnesc28/02-QS-1707.pdf>. Acesso em: 25 mar. 2019.

SUPPES, G. J. et al. Calcium Carbonate Catalyzed Alcoholysis of Fats and Oils. Journal of The American Oil Chemists' Society, Cansas, v. 78, n. 2, p.139-146, 2001. 